\title{
Phase II Testing of Liquid Cooling Garments Using a Sweating Manikin, Controlled by a Human Physiological Model
}

\author{
John Rugh, Charlie King \\ National Renewable Energy Laboratory \\ Heather Paul, Luis Trevino, Grant Bue \\ NASA Johnson Space Center
}

Copyright (C 2006 SAE International

\begin{abstract}
An ADvanced Automotive Manikin (ADAM) developed at the National Renewable Energy Laboratory (NREL) is used to evaluate NASA's liquid cooling garments (LCGs) used in advanced spacesuits. The manikin has 120 separate heated/sweating zones and is controlled by a finite-element physiological model of the human thermoregulatory system. Previous testing showed the thermal sensation and comfort followed expected trends as the LCG inlet fluid temperature was changed. The Phase II test data demonstrates the repeatability of ADAM by retesting the baseline LCG. Skin and core temperature predictions using ADAM in an LCG/arctic suit combination are compared to NASA physiological data to validate the manikin/model. An additional Orlan LCG configuration is assessed using the manikin and compared to the baseline LCG.
\end{abstract}

\section{INTRODUCTION}

NASA currently uses LCGs under spacesuits to remove heat from the human body. Thermally conditioned liquid is circulated through small tubes distributed around the suit. The tubes are secured to the garment in close proximity to the skin. The LCG is expected to remain the major heat acquisition element for removing heat from the crewmember, and improvements to the LCG are needed to reduce its weight by one-half for planetary missions, and to improve its performance. Performance measurements are to be conducted using the best combination of physiological simulations and human tests. Simulations include computer models and manikin thermal tests, and human testing includes laboratory evaluations with the LCG as well as integrated space suit-with-human evaluations to determine final comfort and physiological conditions for candidate LCG designs.

NREL's ADAM is used to assess the thermal performance of LCGs. The manikin's 120 individually controlled surface elements typically have a surface area of $120 \mathrm{~cm}^{2}$. Each segment is a stand-alone device with integrated heating, temperature sensing, sweat distribution, heat flux gauge, and a local controller to manage the closed loop operation of the zone. The sweating surface is constructed entirely of metal, which is optimized for thermal uniformity and response speed. The skin temperature of each zone is determined by an array of thermistors, typically four, on each zone [1].

A unique aspect of ADAM is that it is controlled by a numerical physiological model. As temperatures are controlled and manipulated in ADAM's environment, the resulting skin heat transfer rates are reported to a physiological computer model. The model computes skin and internal temperature distribution and surface sweat rates. This information is sent back to the manikin, which maintains the prescribed skin temperatures, surface sweat rates, and breathing rates. The ongoing loop provides a continuously adjusting measurement tool to assess human thermal comfort in a transient environment. The skin temperature data are also delivered to a thermal comfort model, which predicts human perceptions of comfort.

Validation tests showed the manikin under model control has a human-like skin temperature distribution with some deviations noted in the hands and feet [2]. The predicted overall thermal sensations and comforts match steadystate human data well, although transient measurements show nonhuman-like trends. The testing discussed in this paper is limited to steady-state tests.

During the Phase I testing of NASA LCGs, a series of quick tests were conducted using ADAM to assess a Shuttle LCG [3]. Using the NASA comfort curve (Figure 1) to determine the inlet flow temperature as a function of metabolic rate, three points on the curve were run [4]. ADAM controlled by the physiological model converged quickly at a lower metabolic rate of $200 \mathrm{~W}$. At the higher metabolic rates $(M=275 \mathrm{~W}$ and $350 \mathrm{~W})$, we were not able to attain a steady-state core temperature because of limited test time. We also ran two tests with the inlet temperature over and under the suggested inlet temperature. Overall ADAM's sensation and comfort response to LCG inlet temperature followed the expected 
trends, although results of off-curve test points showed less variation than expected.

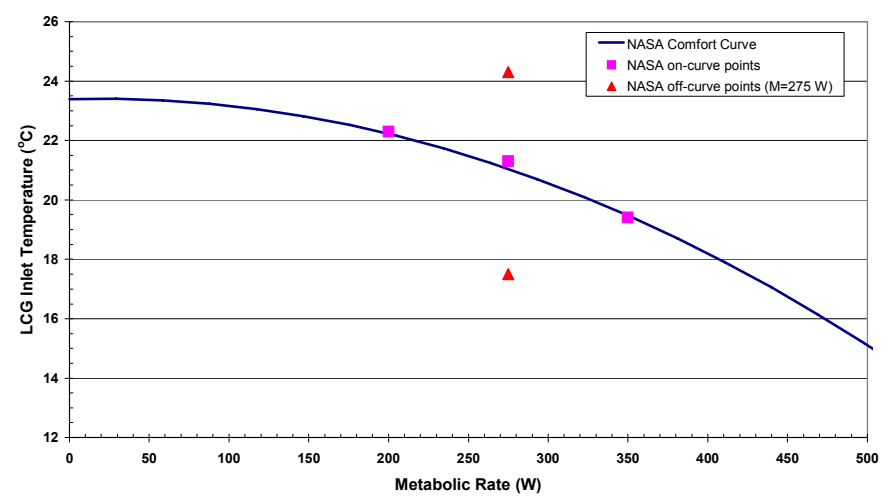

Figure 1. NASA comfort curve

Based on the promising results of Phase I testing, a Phase II test program was initiated. Longer runs were conducted to enable reaching steady state. Additionally, an Orlan LCG was added to the test articles. NREL's manikin environmental chamber was upgraded for Phase II to improve temperature and humidity control.

\section{PHASE II TEST OBJECTIVES}

1. Repeat the baseline Shuttle LCG tests from the Phase $I$ tests to demonstrate repeatability $(M=200$ W).

2. Repeat the baseline Shuttle LCG tests from the Phase I tests to attain steady state $(M=275 \mathrm{~W}$ and $350 \mathrm{~W}$ ).

3. Test the Shuttle LCG with an arctic suit to minimize losses to the environment and better simulate the internal spacesuit environment.

4. Gather data to validate the thermal manikin and model. Compare these data to physiological data generated from previous NASA testing.

5. Test the Orlan LCG for performance comparison.

\section{PHASE II LCG TEST ARTICLES}

\section{SHUTTLE LCG}

The Shuttle LCG is a conformal undergarment that covers the body from the neck to the wrists and ankles (Figure 2). Water flows through the LCG flexible tubing to remove excess metabolic heat from the crew member, and oxygen is vented from the helmet down to the hands and feet for further cooling. The flexible tubing consists of 48 separate tubes in contact with the body, with a total length of approximately 300 feet of one-eighth-inch outer diameter flexible tubes of ethylene vinyl acetate woven into the garment, to carry cooled water and promote heat removal. Additionally, oxygen entering at the helmet is ventilated over portions of the garment via four ducts that pull the vent stream to the extremities. After acquiring heat, the water and air are directed away from the garment.

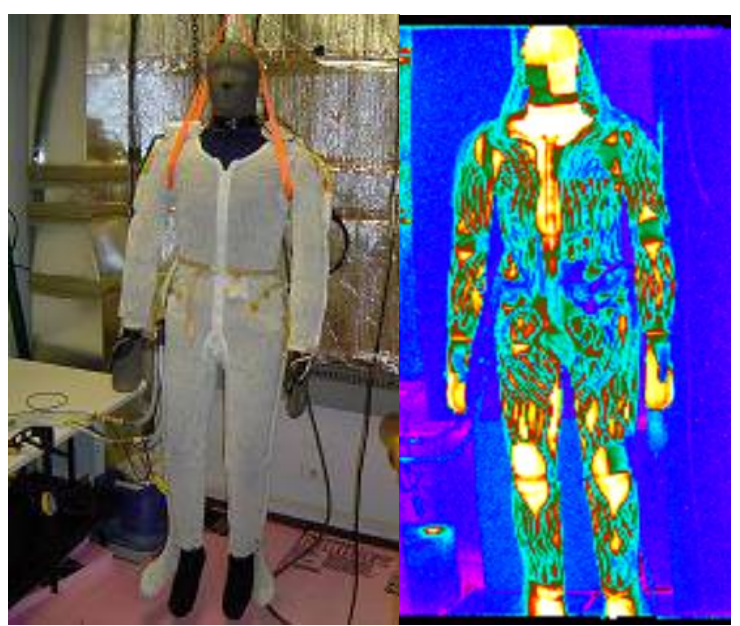

Figure 2. ADAM in the Shuttle LCG

\section{ARCTIC SUIT}

The arctic suit is a two-piece, down-filled outdoor garment manufactured by Marmot (Figure 3 ). The shell is nylon with Gore-Tex while the inner lining is nylon. The pants are a bib style and come up to ADAM's abdomen. The arctic suit was placed over the Shuttle LCG to minimize losses to the environment and better simulate the internal space suit environment.

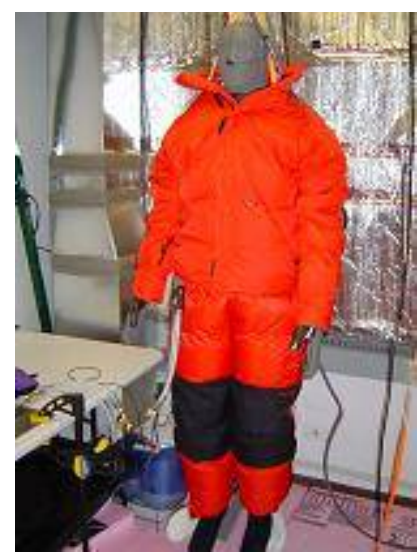

Figure 3. ADAM dressed in the Shuttle LCG and arctic suit

\section{ORLAN LCG}

The Orlan LCG is the Russian-designed cooling garment that provides energy removal for the crew member during suited operations in order to maintain nominal energy storage (Figure 4). Similar to the Shuttle LCG, it is a conformal undergarment that covers the body from the neck to the wrists and ankles, however the flexible tubing extends only to the knee. The Orlan LCG includes a cap designed to be worn over the Communications Carrier Assembly that provides cooling for the head. Water flows through the flexible tubing to remove excess metabolic heat from the crew member. The Orlan LCG consists of $5 \mathrm{~mm}$ outer diameter PVC tubing woven through Knitted Capron elastic fabric with two connections: inlet and outlet, for the supplied cooling 
water. The total tubing length is about $65 \mathrm{~m}$, and the mass with water is less than $3 \mathrm{~kg}$.

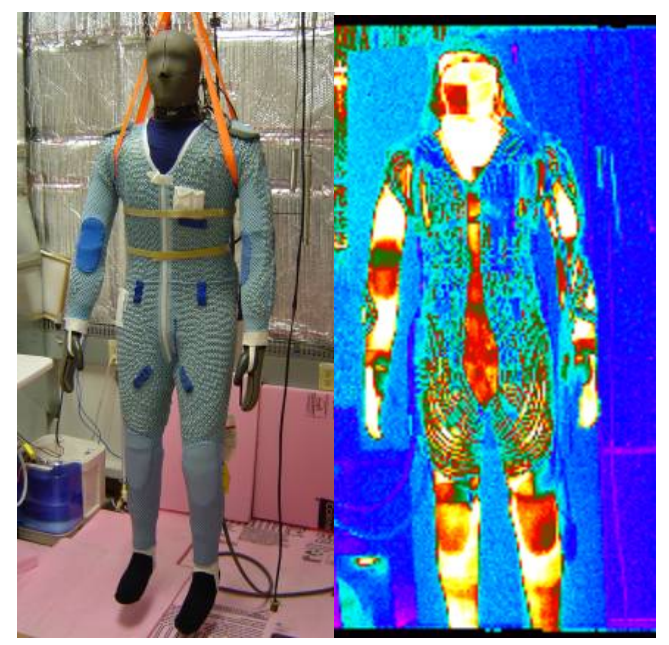

Figure 4. ADAM in the Orlan LCG

\section{ENVIRONMENT TEST CHAMBER}

Several improvements have been made to the environmental chamber since the Phase I testing. Measuring approximately $2.5 \mathrm{~m}$ by $2.5 \mathrm{~m}$, the room has a dedicated heating, ventilation, and air-conditioning (HVAC) system installed to provide humidity, temperature control, and air recirculation. The control system maintains temperatures between $15^{\circ} \mathrm{C}$ and $38^{\circ} \mathrm{C}$. Temperature input to the controller is obtained from a thermocouple suspended in the center of the room. The humidity can be controlled between approximately $20 \%$ and $100 \%$ depending on the room temperature set points. A portable dehumidifier is available when high humidity in the building makes achieving the lower humidity levels difficult. Humidity input to the controller is obtained from a capacitance style humidity sensor suspended in the center of the room. The HVAC system has a $250 \mathrm{cfm}$ blower that circulates air within the room. Air is exhausted into the room along two sides of the ceiling directed down along the walls. The air return is at 1 foot above the floor in one corner of the room. Typical airflow velocity in the middle of the room where the manikin is positioned is approximately $0.1 \mathrm{~m} / \mathrm{sec}$.

In practice, relative humidity can be controlled to $\pm 1 \%$, and temperature surveys have shown less then $0.4^{\circ} \mathrm{C}$ variation from floor to ceiling in the center of the room. The air temperature is measured with type $K$ thermocouples located at head, waist, and foot level. The wall, ceiling, and floor temperature are also measured. The thermocouples were calibrated using a Hart model 7103 Micro-Bath calibrator.

In order to provide repeatable cooling for the LCG, a Neslab water chiller was installed. This unit can provide up to $2500 \mathrm{~W}$ of heat removal, and maintain $\pm 0.1^{\circ} \mathrm{C}$ temperature stability. Chilled water flows through the LCG and is measured by a Dwyer Model TF1053 flow sensor. Temperature into and out of the LCG is monitored by thermocouples in the fluid stream as close to the LCG as possible. A series of valves is used to throttle the output of the chiller pump to a flow of 1.81 $\mathrm{I} / \mathrm{min}$ through the suit.

A data acquisition system-composed of a laptop computer and National Instruments hardware-collects room temperature, humidity, chilled water flow rate, and water inlet/outlet temperatures.

\section{TEST PROCEDURE}

First ADAM was dressed in polypropylene underwear with a long-sleeve top and bottom. This is the base layer typically used by NASA, and it also facilitated dressing ADAM in the LCG. When the LCGs were put on ADAM, a less than perfect fit was noted in some areas. A single Velcro strap around the chest was used to provide a snug fit between the Shuttle LCG to ADAM; two straps in the chest area were necessary on the Orlan LCG. Excess material in the crotch area of the Orlan LCG was bundled using cable ties. A sling under the arms supported ADAM in a standing position. Care was taken to not restrict flow in the tubing in the underarm/shoulder area.

We performed two types of LCG tests with ADAM; model control and constant temperature control.

\section{MODEL CONTROL}

In model control, the physiological model controls the manikin, so it responds in a human-like manner. At the start of a run, the manikin is initialized with a constant temperature of $32^{\circ} \mathrm{C}$ and a sweat rate of $25.44 \mathrm{ml} / \mathrm{hr} / \mathrm{m}^{2}$. The chiller is set to the desired inlet temperature and flow is initiated to the LCG. The model is started using the heat loss from the previous run as the boundary condition. After 30 minutes, the manikin is linked to the model. The manikin receives the skin temperature and sweat flow-rate set points from the model, and sends real-time heat loss from each segment to the model. The test is determined to reach steady state when the core temperature stabilizes.

The room temperature was set at $27^{\circ} \mathrm{C}$, which yielded a spatially averaged air temperature of $26.6^{\circ} \mathrm{C}$ at ADAM. The room humidity was maintained at $25 \%$. The room was typically conditioned overnight.

\section{TEMPERATURE CONTROL}

Constant temperature runs were performed to eliminate variability associated with model control and quantify differences in LCG performance. The manikin was set at a constant skin temperature of $35^{\circ} \mathrm{C}$. Sweat flow rates of 0 and $200 \mathrm{ml} / \mathrm{hr} / \mathrm{m}^{2}$ were run. After ADAM's heat loss attained steady state with no flow, flow to the LCG was initiated. The run was terminated when the heat loss with LCG flow reached steady state. 
For these runs, the room temperature was set at $23^{\circ} \mathrm{C}$, which yielded an average air temperature of $22.4^{\circ} \mathrm{C}$ around ADAM. The room humidity was set at $50 \%$.

\section{RESULTS}

\section{REPEATABILITY TESTS}

To assess repeatability, we performed tests in the same environmental and control conditions as the 2005 test program. The manikin environmental chamber was set at $27^{\circ} \mathrm{C}$, and the relative humidity was $25 \%$. ADAM was dressed in the Shuttle LCG as shown in Figure 2. The physiological model was run with a metabolic rate of 200 W while the inlet fluid temperature ( $\left.T_{\text {inlet }}\right)$ to the LCG was $22.4^{\circ} \mathrm{C}$, and the flow was $1.81 \mathrm{l} / \mathrm{min}$. After the Orlan LCG testing, ADAM was again dressed in the Shuttle LCG to obtain the additional data point on $5 / 8 / 06$. Table 1 shows the core temperature was within $0.04^{\circ} \mathrm{C}$ on the test runs. The average skin temperature shows a larger variation of $0.4^{\circ} \mathrm{C}$ with the outliner appearing to be the $3 / 14 / 06$ data point. The primary reason for this difference is that the back skin temperature is $1.6^{\circ} \mathrm{C}$ warmer. This caused the back thermal sensation to be hot on $3 / 14 / 06$ while it is neutral on 5/8/06. While the overall sensation in Table 1 combines all parts of the body, the high weighting of the back sensation causes a greater impact on the overall sensation and overall comfort.

Table 1. Shuttle LCG with $M=200 \mathrm{~W}, \mathrm{~T}_{\text {inlet }}=22.4^{\circ} \mathrm{C}$

\begin{tabular}{|c|c|c|c|c|}
\hline & $\begin{array}{c}\text { Core Temperature } \\
\left({ }^{\circ} \mathrm{C}\right)\end{array}$ & $\begin{array}{c}\text { Average Skin } \\
\text { Temperature }\left({ }^{\circ} \mathrm{C}\right)\end{array}$ & $\begin{array}{c}\text { Overall Thermal } \\
\text { Sensation }(+/-4)\end{array}$ & $\begin{array}{c}\text { Overall Thermal } \\
\text { Comfort }(+/-4)\end{array}$ \\
\hline $2 / 15 / 05$ & 36.71 & 32.56 & 0.35 & 1.63 \\
\hline $3 / 14 / 06$ & 36.75 & 32.97 & 0.79 & 0.98 \\
\hline $5 / 8 / 06$ & 36.75 & 32.68 & 0.39 & 1.45 \\
\hline
\end{tabular}

Both sensation and comfort are evaluated on a scale of -4 to +4 . For sensation, positive values indicate that one is feeling hot, and negative values indicate that one is feeling cold. For comfort, the scale rising from negative to positive indicates being very uncomfortable (-4) to very comfortable $(+4)$. Table 2 defines the intermediate values.

Table 2. Thermal sensation and comfort scales

\begin{tabular}{|c|l|l|}
\hline $\begin{array}{c}\text { Numerical } \\
\text { Value }\end{array}$ & $\begin{array}{c}\text { Sensation } \\
\text { Scale }\end{array}$ & Comfort Scale \\
\hline 4 & very hot & very comfortable \\
\hline 3 & hot & \\
\hline 2 & warm & \\
\hline 1 & slightly warm & just comfortable \\
\hline 0 & neutral & \\
\hline-1 & slightly cool & just uncomfortable \\
\hline-2 & cool & \\
\hline-3 & cold & \\
\hline-4 & very cold & very uncomfortable \\
\hline
\end{tabular}

An investigation was conducted into why the back temperature was higher for the 3/14/06 test. The back temperature was compared to the chest temperature for all the runs. In the Shuttle LCG tests in March, the back temperature was warmer than the chest in all cases. In the 2005 and the 5/8/06 tests, the back was cooler than the chest. We noted gaps between the Shuttle LCG and ADAM's upper-back region despite the strap used to bring the LCG in contact with ADAM as was done in 2005. Although adjustments were made to the suit fit, it appears we did not have good contact in the upper-back region on $3 / 14 / 06$.

We also looked at test-to-test variation with ADAM dressed in the Orlan LCG. We ran the same room, fluid, and control conditions as above without changing the suit fit. The resulting core temperature was the same for both runs, and the average skin temperature was only different by $0.13^{\circ} \mathrm{C}$ (Table 3). The overall sensation was within 0.05 , and the overall comfort was within 0.07 . It appears there is good repeatability test-to-test with the hands and feet showing the largest deviations. We used core temperature to determine steady state. In the future, we need to monitor all skin temperatures because hand/foot temperatures appear to be changing when the core temperature is constant.

Table 3. Orlan LCG with $\mathrm{M}=200 \mathrm{~W}, \mathrm{~T}_{\text {inlet }}=22.4^{\circ} \mathrm{C}$

\begin{tabular}{|c|c|c|c|c|}
\hline & $\begin{array}{c}\text { Core Temperature } \\
\left({ }^{\circ} \mathrm{C}\right)\end{array}$ & $\begin{array}{c}\text { Average Skin } \\
\text { Temperature }\left({ }^{\circ} \mathrm{C}\right)\end{array}$ & $\begin{array}{c}\text { Overall Thermal } \\
\text { Sensation }(+/-4)\end{array}$ & $\begin{array}{c}\text { Overall Thermal } \\
\text { Comfort }(+/-4)\end{array}$ \\
\hline $5 / 1 / 2006$ & 36.64 & 32.74 & 0.41 & 1.18 \\
\hline $5 / 2 / 2006$ & 36.64 & 32.87 & 0.48 & 1.13 \\
\hline
\end{tabular}

\section{MODEL CONTROL}

In the 2005 test program, the limited test time prevented us from attaining steady-state conditions for the $\mathrm{M}=275$ $\mathrm{W}\left(\mathrm{T}_{\text {inlet }}=17.5,21.3\right.$, and $\left.24.3^{\circ} \mathrm{C}\right)$ and the $\mathrm{M}=350 \mathrm{~W}$ $\left(T_{\text {inlet }}=19.4 C\right)$ test points. With adequate time, we ran all five test points in Figure 1 to steady state with the Shuttle LCG (Figure 2) and the Orlan LCG (Figure 4). The arctic suit was not used for this series of tests; therefore, the exterior of both LCGs were exposed to the same room conditions. While the environment around the LCG for these tests is different than inside a spacesuit, the consistent room conditions allow for thermal performance comparison. There was no airflow supplied to the ventilation ducts in the Shuttle LCG.

A flow rate of $1.81 \mathrm{l} / \mathrm{min}$ was used in all tests. It took 3-4 hours to reach steady state for $\mathrm{M}=275 \mathrm{~W}$ and 7 hours for $M=350 \mathrm{~W}$. At the higher metabolic rates and inlet temperatures, the core temperature initially overshoots due to a lag in sweat evaporative cooling, which subsequently causes excessive sweating. This sweat (dionized water) flows into the segments, evaporates, and causes a resulting undershoot in core temperature.

The Orlan LCG is equipped with a head covering fed by four tubes, which come up the center of the back. We did not use the head covering during this test program because the Shuttle LCG did not have a head covering. 
The authors recognize cooling the head would have a significant impact on thermal sensation, but it was beyond the scope of this test program. Localized cooling of the head also causes problems with the model. Since the core temperature is currently defined as the volume average of the brain, the model is too sensitive to localized head cooling.

Figure 5 shows the core temperature for the Orlan LCG was an average of $0.06^{\circ} \mathrm{C}$ lower than the Shuttle LCG for all tests. Since the sweat rate is a function of core temperature in the model, the Orlan LCG also has lower sweat rates. The heat transfer to the LCG fluid in Figure 6 was on average $15 \mathrm{~W}$ greater with the Orlan suit indicating the improved heat transfer compared to the Shuttle LCG.

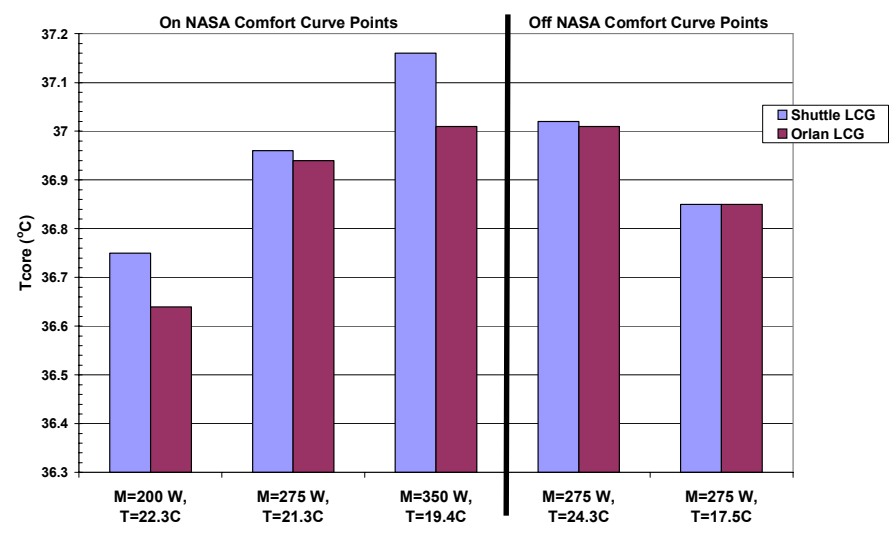

Figure 5. Core temperature for Shuttle and Orlan LCGs

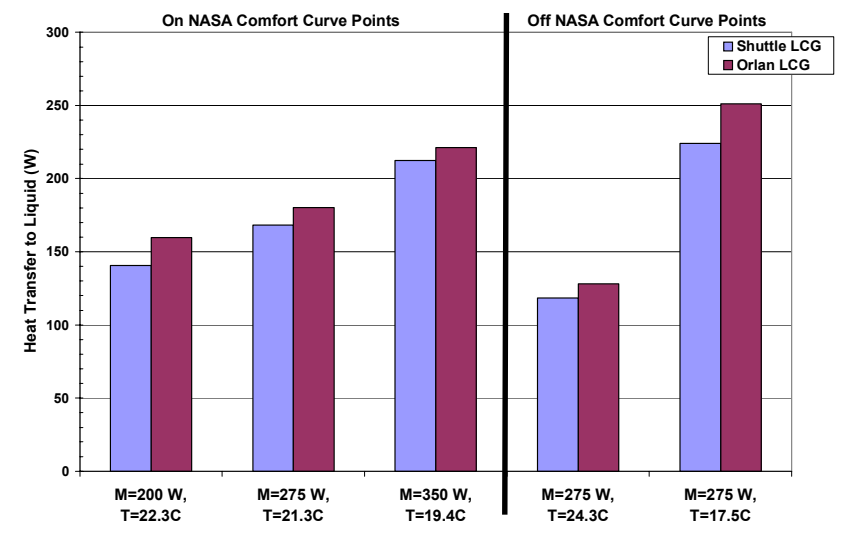

Figure 6. Liquid heat transfer for Shuttle and Orlan LCGs

The skin temperature results in Figure 7 are not as consistent. Since the Shuttle LCG did not have good contact in the upper back area, the average skin temperature for both garments was calculated without including the back. While the Orlan LCG resulted in a lower average skin temperature in two cases, a higher average skin temperature resulted during the lowest fluid inlet temperature cases. This is because the Orlan LCG does not have cooling tubes in the calf region. The Shuttle LCG has tubes and subsequently lower calf temperatures. This also lowers the foot temperatures due to cooler blood flow and results in a lower overall average skin temperature. The dashed lower curves in Figure 8 present the average skin temperature without the back for three inlet temperature cases at $M=275 \mathrm{~W}$ (same data as Figure 7). At $\mathrm{T}_{\text {inlet }}=17.5^{\circ} \mathrm{C}$, the Orlan LCG has a higher average skin temperature. Taking the calves and feet out of the average (solid lines), the Orlan LCG has significantly lower skin temperatures for the $M=275 \mathrm{~W}$ cases as well as the $M=350 \mathrm{~W}$ and $M=200 \mathrm{~W}$ cases.

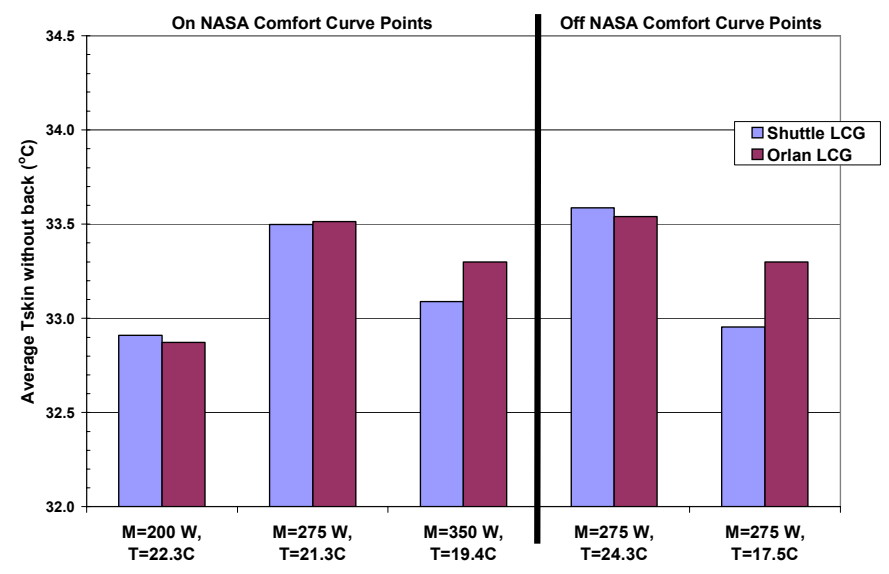

Figure 7. Average skin temperature without the back for Shuttle and Orlan LCGs

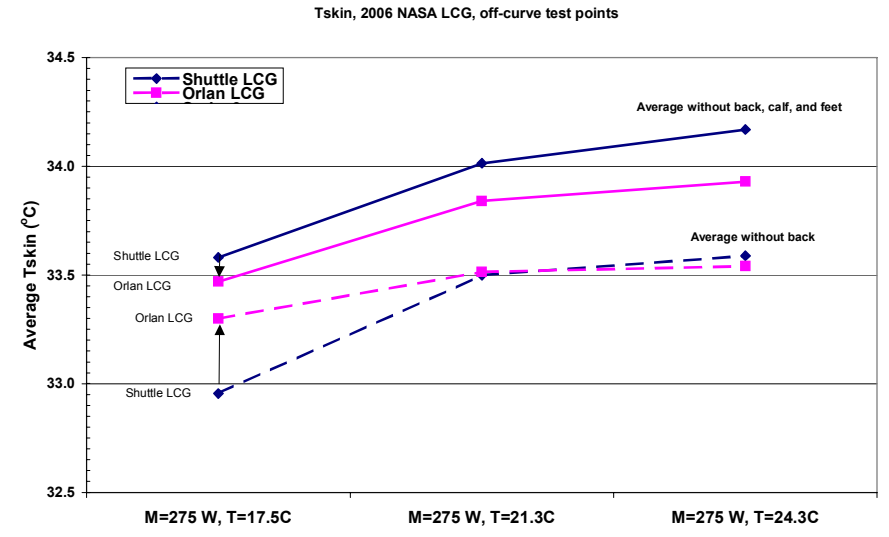

Figure 8. Skin temperatures for $\mathrm{M}=275 \mathrm{~W}$ cases

In the $T_{\text {inlet }}=17.5^{\circ} \mathrm{C}$ case, the calf temperature in the Orlan LCG was actually warmer than the $T_{\text {inlet }}=24.3$ case. This is due to the higher sweating in the $\mathrm{T}_{\text {inlet }}=24.3^{\circ} \mathrm{C}$ case cooling the calf due to the evaporation. In the $T_{\text {inlet }}=17.5^{\circ} \mathrm{C}$ case, the basal sweat rate didn't significantly cool the calf and resulted in a higher skin temperature.

The overall thermal sensation is plotted in Figure 9. As the fluid inlet temperature is increased, the thermal sensations become increasing warm as expected, although the slope is not very steep. The Orlan LCG resulted in cooler (less warm) thermal sensation. In all three cases, the Orlan LCG calf and foot local thermal sensations were warmer than the Shuttle LCG, but the 
sensation correlations weights more influential parts of the body higher.

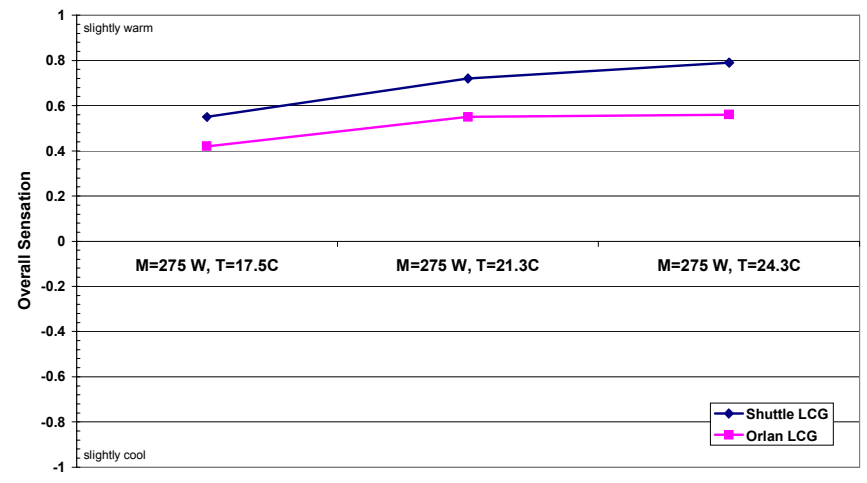

Figure 9. Overall thermal sensation for $\mathrm{M}=275 \mathrm{~W}$ cases

We used an unweighted average of the local comforts to calculate the overall thermal comfort (Figure 10). At warmer inlet temperatures, the Orlan LCG had better comfort. At $17.5^{\circ} \mathrm{C}$ inlet temperature, the Orlan LCG had reduced comfort. This was due to local discomfort at the calf and foot of the Orlan LCG. The local sensation is warmer due to the skin temperature difference between the calf and rest of the body, and this causes local discomfort.

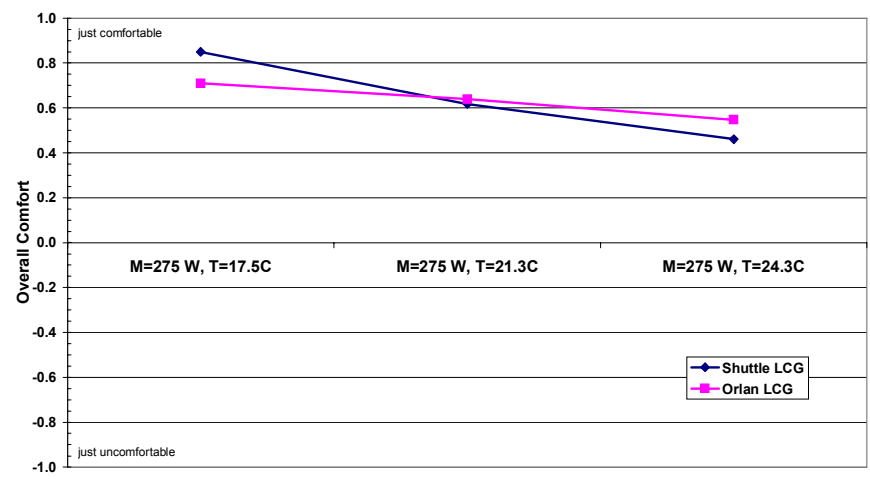

Figure 10 . Overall thermal sensation for $M=275 \mathrm{~W}$ cases

The Orlan LCG has better thermal performance than the Shuttle LCG using the following parameters: core temperature, heat transfer to the liquid, and average skin temperature (without back, calves, and feet). These tests were performed with the less than optimum Shuttle LCG contact in the upper back region of ADAM. Based on the multiple tests at $M=200 \mathrm{~W}$, the Shuttle LCG thermal sensation and comfort results would be better than presented in Figures 9 and 10, but the magnitude is unknown at this time.

\section{ARCTIC SUIT}

The Shuttle LCG was tested underneath the arctic suit (Figure 3) to reduce the impact of the room conditions and enable comparison to NASA data where subjects were tested with the arctic suit /Shuttle LCG combination. The room conditions were set to $27^{\circ} \mathrm{C}$ and $25 \%$ relative humidity to be consistent with the Shuttle and Orlan LCG tests. Since the room was at $26.6^{\circ} \mathrm{C}$ and the fluid inlet temperature was $22.3^{\circ} \mathrm{C}$, the arctic suit should have reduced the heat gain from the room air or at least had negligible impact. This did not happen. We ran five model control cases: one at $M=200 \mathrm{~W}$, three at $M=300$ $\mathrm{W}$, and one at $\mathrm{M}=350 \mathrm{~W}$. At the higher metabolic rates, the initial transient caused excessive sweat that soaked the arctic suit. This liquid remained in the arctic suit and caused the heat transfer to the liquid to be approximately $30 \%$ higher than with no arctic suit. The excessive liquid surrounding ADAM caused four segments to fail. It was decided not to test the Orlan LCG under the arctic suit because of the increased heat transfer to the liquid and to reduce the chances of additional damage to ADAM.

We were able to gather meaningful data from the arctic suit tests despite the problems encountered. In the $M=200 \mathrm{~W}$ case, ADAM did not over-sweat initially and had:

- Reasonably dry skin

- About the same fluid side heat transfer as the LCG only test

- $\quad$ Core and skin temperatures slightly warmer due to insulation of the segments not covered by the tubes.

These skin temperature data were compared to physiological data measured by NASA [5]. In that test program, human subjects were dressed in the base layers, Shuttle LCG, and arctic suit. Skin temperatures were measured over various parts of the body, and the heart rate was recorded. The subjects exercised on a treadmill. A wide range of inlet temperatures and metabolic rates were tested. Two of the subjects had metabolic rates and inlet fluid temperatures close to our test conditions $\left(\mathrm{M}=200 \mathrm{~W}\right.$ and $\left.22.4^{\circ} \mathrm{C}\right)$ that enabled comparison. At this metabolic rate, the test report indicates the arm push bars were not used while the subject walked on the treadmill.

Figure 11 shows the arm and torso temperatures predicted by ADAM are similar to the NASA subjects. A single point on the forearm defines the right arm location while the torso is an average of the chest and back. The right leg is an average of the calf and thigh. The leg temperatures predicted by ADAM were approximately $4^{\circ} \mathrm{C}$ warmer than the NASA subjects. This may be due to the pumping action of the clothing during the leg motion of the subjects on the treadmill, which cooled the leg. Variations in temperature measurement location also add uncertainty. 


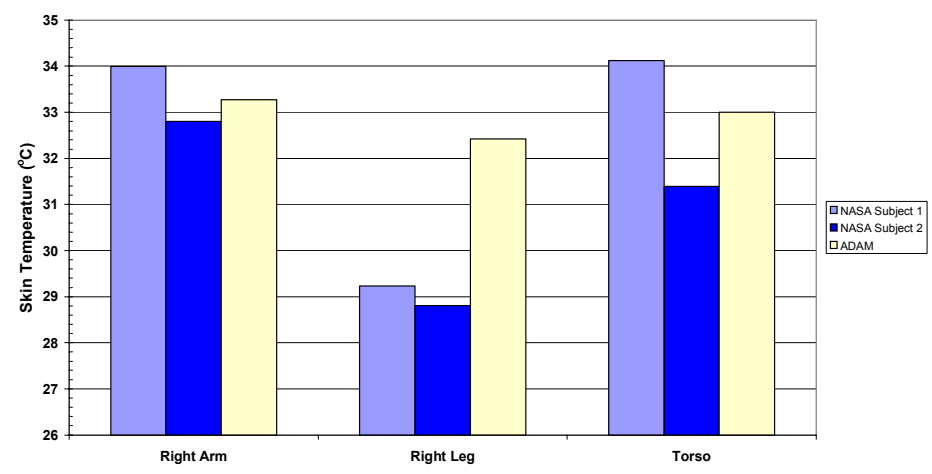

Figure 11. Comparison to NASA subject data

A limitation of this comparison is that the room conditions of the NASA test were not known. It is assumed the arctic suit isolated the subjects from the room environment and reduced its impact.

\section{CONSTANT TEMPERATURE TESTS}

In order to eliminate variables associated with the model, we also conducted tests at a constant skin temperature of $35^{\circ} \mathrm{C}$ with and without sweat. The liquid side heat gain is calculated by

$\mathrm{Q}_{\text {liquid }}=\mathrm{mc}_{\mathrm{p}}\left(\mathrm{T}_{\text {outlet }}-\mathrm{T}_{\text {inlet }}\right)$

The heat loss from ADAM is calculated by summing the heat loss from all 120 segments.

$Q_{\text {ADAM }}=\sum_{n=1}^{120} Q_{n}{ }^{\prime \prime} A_{n}$

By calculating the heat loss from ADAM without LCG flow and with LCG flow, the difference is the heat loss due to the flow as measured by ADAM.

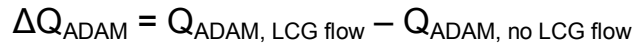

The columns on the right side of Figure 12 show the increase in heat loss measured by ADAM due to the evaporation of the sweat. The $\Delta Q_{A D A M}$ parameter was calculated for the no sweat case and sweat case. The difference between these two cases shows that sweat increased the heat loss by $46 \mathrm{~W}$ when flow was supplied to the LCG. There was a similar $34 \mathrm{~W}$ increase in $\mathrm{Q}_{\text {liquid }}$ due to the presence of sweat. This increase in heat transfer is due to increased thermal conductivity of the liquid between the $T_{\text {skin }} /$ tubing in the LCG and condensation of the sweat vapor on the tubes.

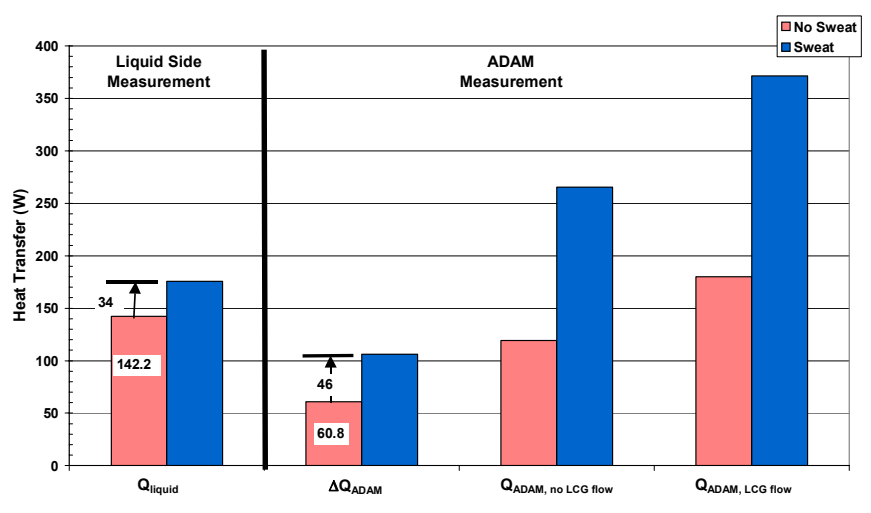

Figure 12. Shuttle LCG and ADAM heat transfer for no sweat and sweat conditions

One concern is the difference between $Q_{\text {liquid }}$ and $\Delta Q_{A D A M}$. For the no sweat case, the $\Delta Q_{A D A M}=60.8 \mathrm{~W}$ while the $Q_{\text {liquid }}=142.2 \mathrm{~W}$. The following reasons are considered:

- Condensation on the tubes increase $Q_{\text {liquid }}$ (not likely, test at low humidity showed negligible change in heat transfer)

- $Q_{\text {liquid }}$ larger due to heat transfer from the room [not likely since the typical average LCG fluid temperature $\left(23.1^{\circ} \mathrm{C}\right)$ is greater than the air temperature $\left.\left(22.5^{\circ} \mathrm{C}\right)\right]$

- Uncertainty in $\mathrm{Q}_{\text {liquid }}$ calculation (estimated to be +/$18 \mathrm{~W}$ )

- Uncertainty in $\mathrm{Q}_{\mathrm{ADAM}}$ calculation (possible, but core temperatures and skin temperatures look okay)

- Heat transfer from ADAM's interior to the liquid (possible, there is internal heating in ADAM and we measured a $71 \mathrm{~W}$ difference between the power supplying ADAM and the measured heat loss from the segments).

This issue is not resolved at this time, but comparisons between the Shuttle and Orlan LCGs continue. The Shuttle LCG tests were conducted with good contact in the upper back region. Figure 13 shows a comparison of the Shuttle and Orlan LCGs with no sweat. The Orlan LCG had a higher heat loss with no flow suggesting a lower baseline thermal resistance of the Orlan suit. This makes sense since the Shuttle LCG has two layers of material and is expected to have higher thermal resistance. The fluid side heat transfer is $4 \mathrm{~W}$ higher for the Orlan LCG suggesting better heat transfer, although the magnitude is not significant. This slightly better performance is consistent with the model control tests. 


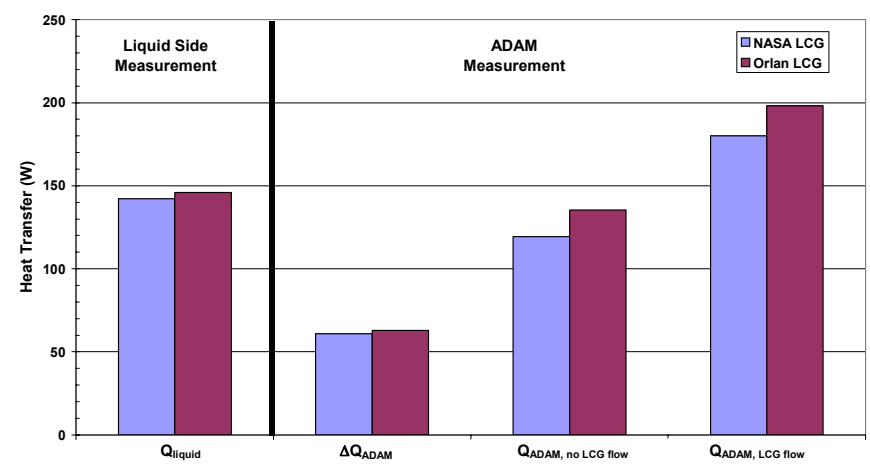

Figure 13. Comparison of NASA and Orlan LCGs with no sweat

\section{CONCLUSION}

ADAM was successfully used to assess the thermal performance of a Shuttle and Orlan LCG. Using a manikin controlled by a physiological mode enabled us to assess differences in local skin temperatures, thermal sensations, and thermal comforts.

Repeating a test that was run in 2005 demonstrated the importance of verifying a good fit of the LCG on ADAM prior to testing. Some of the Shuttle LCG model control tests were run with a less than perfect fit, which made comparison to the Orlan LCG challenging. Variation in test-to-test results was low. Differences were attributed to not attaining steady-state skin temperatures in all regions.

Constant skin temperature tests showed that sweat impacts the performance of LCGs through increased thermal conductivity due to moisture between the skin and tubes, and the condensation on the tubes. A comparison of skin temperatures from a model control run with NASA subject data showed reasonably good correlation. ADAM may have overestimated the leg temperature because he was not walking like the subjects in Reference 5.

Comparing results with the same manikin and room conditions, the Orlan LCG had slightly better heat transfer, which resulted in lower core and skin temperatures. The less than perfect fit on the upper back of the Shuttle LCG prevented a good comparison of thermal sensation and comfort.

\section{RECOMMENDATIONS}

The physiological model should be improved to better simulate hand/foot temperatures. The impact of the definition of core temperature needs to be further investigated. If the core temperature were less sensitive to the brain temperature, additional testing could be performed to assess the impact of the head portion of the Orlan LCG. Using an average temperature instead of an individual segment temperature to provide input to the thermal comfort model correlations would reduce the impact a single segment has on thermal sensation and comfort.

Further tests can be conducted under a spacesuit although venting would be required to avoid the moisture retention problem identified in the arctic suit testing. ADAM can help design the next generation NASA LCG by assessing the thermal performance of potential configurations and even assisting in a physiological based LCG design.

\section{ACKNOWLEDGMENTS}

The authors gratefully acknowledge the support of the U.S. Department of Energy (DOE) in developing, fabricating, and testing the thermal manikin and physiological model. DOE's Office of FreedomCAR and Vehicle Technologies (OFCVT) supported this work. The authors appreciate the support of Lee Slezak, DOE Program Manager; Terry Penney, NREL's OFCVT Technology Manager; and Barbara Goodman, Director of the NREL Center for Transportation Technologies and Systems.

\section{REFERENCES}

1. Rugh, J.; Farrington R.; Bharathan, D.; Vlahinos, A.; Burke, R.; Huizenga, C.; and Zhang, H. (2004) Predicting Human Thermal Comfort in a Transient Nonuniform Thermal Environment, European Journal of Applied Physiology, (Vol. 92, Number 6) pp. 721727.

2. Rugh, J.; and Bharathan, D. (2005) "Predicting Human Thermal Comfort in Automobiles," Proceedings of the 7th Vehicle Thermal Management Systems Conference, Paper \# 200501-2008, May 10-12, 2005, Toronto, Canada, Society of Automotive Engineers.

3. Farrington, R.; Rugh, J.; Bharathan, D.; Paul, H.; Bue, G.; and Trevino, L. (2005) "Using a Sweating Manikin, Controlled by a Human Physiological Model, to Evaluate Liquid Cooling Garments," Proceedings of the 35th International Conference on Environmental Systems, Paper \# 2005-01-2971, July 11-14, 2005, Rome, Italy, Society of Automotive Engineers.

4. Dunaway, B. (1988) Automatic Liquid and Ventilation Cooling Garment Control Algorithm Final Test Report, NASA Document SSS87-221 (CTSD-SS176).

5. Smith, G., and Pantermuehl, J. (1992) Segmented Liquid Cooled Garment Final Test Report, NASA Document JSC-25720 (CTSD-ADV-032).

\section{CONTACT}

Grant Bue, M.S.M.E., leads the Extravehicular Activity (EVA) worksite thermal analysis for the International Space Station at the NASA Johnson Space Center. He was involved in the design and testing of liquid cooling 
systems for the Shuttle Launch/Entry Suit. He is coauthor of the computer program ASDA: Advanced Suit Design Analyzer. $\mathrm{He}$ can be reached at grant.c.bue@nasa.gov.

Charles King is an engineer at NREL. He ran the tests and is responsible for maintaining ADAM and the manikin environmental chamber. He can be reached at charles_king@nrel.gov.

Heather Paul is a part of the Advanced EVA Team at the NASA Johnson Space Center. She is the Ventilation Subsystem manager for the development of the next generation Portable Life Support Systems that will be used with the Lunar and Martian spacesuits. She also works with the Thermal Subsystem on evaluating cooling garment concepts. She can be reached at heather.I.paul@nasa.gov.

John Rugh, M.S.M.E., leads the Vehicle Ancillary Loads Reduction task at NREL. The objective of the project is to reduce fuel used for vehicle ancillary loads by reducing thermal loads, improving delivery efficiency, and increasing equipment efficiency including using engine waste heat to provide cabin cooling. He can be reached at john_rugh@nrel.gov.

Luis Trevino is a part of the Advanced EVA Team at the NASA Johnson Space Center. $\mathrm{He}$ is the Thermal Subsystem manager for the development of the next generation Portable Life Support Systems that will be used with the Lunar and Martian spacesuits. He can be reached at luis.trevino-1@nasa.gov.

\section{DEFINITIONS, ACRONYMS, ABBREVIATIONS}

$\begin{array}{ll}A_{n} & \text { ADAM segment area } \\ \text { ADAM } & \text { ADvanced Automotive Manikin } \\ C_{p} & \text { Specific heat of LCG fluid } \\ \text { DOE } & \text { U.S. Department of Energy } \\ \text { EVA } & \text { Extravehicular Activity } \\ \text { HVAC } & \text { Heating, ventilation, and air-conditioning } \\ \text { LCG } & \text { Liquid cooling garment } \\ M & \text { Metabolic rate } \\ m & \text { LCG liquid mass flow } \\ \text { NREL } & \text { National Renewable Energy Laboratory } \\ \text { OFCVT } & \text { Office of FreedomCAR and Vehicle } \\ & \text { Technologies } \\ Q_{n}{ }^{\prime} & \text { ADAM segment heat transfer } \\ Q_{A D A M} & \text { Sum of the heat transfer from ADAM's } \\ \Delta Q_{A D A M} & \text { 120 segments } \\ & \text { Difference in } Q_{\text {ADAM }} \text { without LCG flow } \\ \mathrm{Q}_{\text {liquid }} & \text { and with LCG flow } \\ \mathrm{T}_{\text {inlet }} & \text { LCG liquid heat gain } \\ \mathrm{T}_{\text {outlet }} & \text { LCG inlet fluid temperature } \\ & \text { LCG outlet fluid temperature }\end{array}$

